\title{
ICT and the environment in developing countries: opportunities and developments
}

\author{
John Houghton \\ Centre for Strategic Economic Studies, Victoria University, AUSTRALIA \\ John.Houghton@vu.edu.au
}

[6,500 words, excluding references]

\section{Introduction}

Both developed and developing countries face many environmental challenges, including climate change, improving energy efficiency and waste management, addressing air pollution, water quality and scarcity, and loss of natural habitats and biodiversity. This paper explores how the Internet and the ICT and related research communities can help tackle environmental challenges in developing countries through more environmentally sustainable models of economic development, and examines the status of current and emerging environmentally friendly technologies, equipment and applications in supporting programs aimed at addressing climate change and improving energy efficiency. Discussion focuses on the role of ICTs in: $(i)$ climate change mitigation (e.g. investing in smart transport and energy efficient infrastructure); (ii) mitigating other environmental pressures (e.g. biodiversity loss, water and soil pollution); (iii) climate change adaptation (e.g. adapting to rising sea levels, droughts, desertification); and (iv) international co-operation (e.g. technology transfer and the development of sustainable ICT value chains). This paper provides an overview and points to examples of current activities and opportunities in each of these areas.

\section{ICT and the knowledge-based economy}

A major feature of the knowledge-based economy is the impact that ICTs have had on industrial structure, with a rapid growth of services and a relative decline of manufacturing. Services are typically less energy intensive and less polluting, so among those countries with a high and increasing share of services, we often see a declining energy intensity of production - with the emergence of the Knowledge Economy ending the old linear relationship between output and energy use (i.e. partially de-coupling growth and energy use).

Estimating that in the United States around one-third of the increase in energy efficiency could be attributed to structural change in the economy and the remaining two-thirds to improved energy efficiency, Romm et al. (2000) concluded that forecasts for energy consumption and emissions of carbon dioxide to 2010 for the North American economy should be adjusted down by around $5 \%$ due to the rapid impact of the Internet economy. More recently, Laitner and Ehrhardt-Matrinez (2008) estimated that for every extra kilowatt hour of electricity that has been used to power ICTs, the US economy has increased its overall energy savings by a factor of 10. That gain in energy efficiency (energy productivity) has enabled the US economy to meet $75 \%$ of the demand for new energy services through energy efficiency gains. 
Traditional development models have focussed on a shift from agriculture to manufacturing, the development of free markets, encouraging exports and industrialisation in labour-intensive consumer goods - a model borne out in The East Asian Miracle (World Bank 1993) and the emergence of China as the World"s largest exporter of ICT and related consumer equipment. Sheehan (2008) suggests a re-think, based on the evidence from the emergence of India and the thrust of China es Eleventh Five Year Plan (2006-11). Looking at long-term trends in employment and sectoral GDP shares and growth rates, Sheehan (2008) suggests that India provides an example of a „big-push ${ }^{\text {ee }}$ development driven by services (Figure 1), and that: "industrialization as it used to be understood is no longer a realistic option for most developing countries, and they need to find ways of participating in the growth of the modern services sector, which can directly improve the living standards of their people." It is notable that India's $\mathrm{CO}_{2}$ intensity per unit of GDP is substantially lower than is typical of developing countries, comparable to that of Japan and lower than Germany"s (Ghosh 2009).

Figure 1: $\quad$ Value added shares by sector, India $1950-51$ to $2007-08$

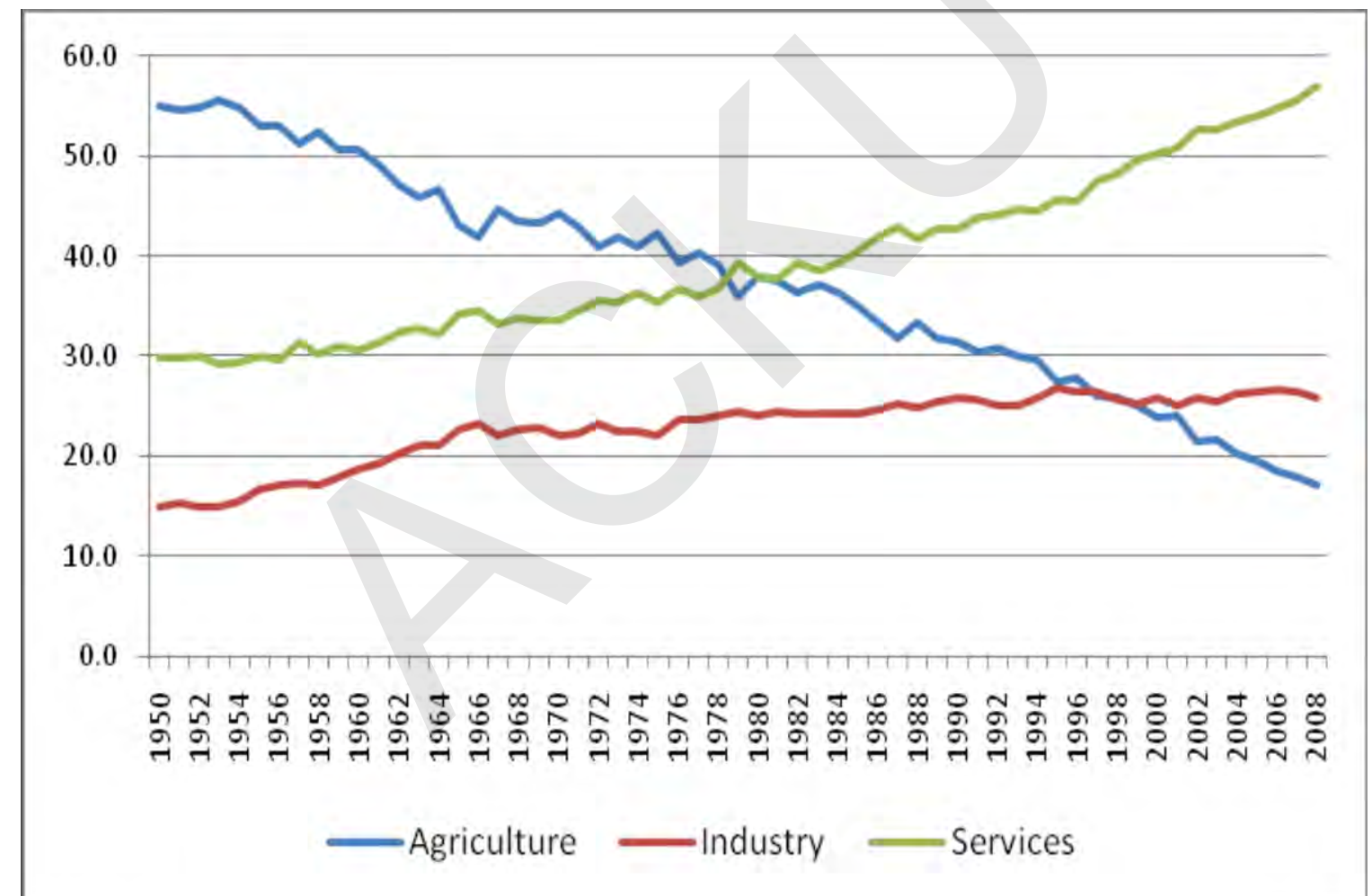

Source: Sheehan, P.J. (2008) Beyond Industrialization: New Approaches to Development Strategy Based on the Services Sector, UNU-WIDER Research Paper 2008/60: Helsinki.

ICTs have played a key role in making services tradeable and the globalisation of IT and ITenabled services. Looking at the intensity of IT and IT enabled services exports, Houghton and Welsh (2009) note that in only four countries did computer and information services account for more than $25 \%$ of total services exports during 2006 - India, where they accounted for almost $40 \%$ (down from $50 \%$ in 2004), Ireland $31 \%$ (down from 39\% in 2004), and Israel $27 \%$ (Figure 2). Their analysis suggests that IT and IT-enabled services exports can play an important role in a wide range of developed, emerging and developing economies, and may in the latter provide 
the basis for a more environmentally sustainable development path than has characterised industrialisation in the past.

Figure 2: $\quad$ Share of IT services in total services exports, 2006 (per cent)

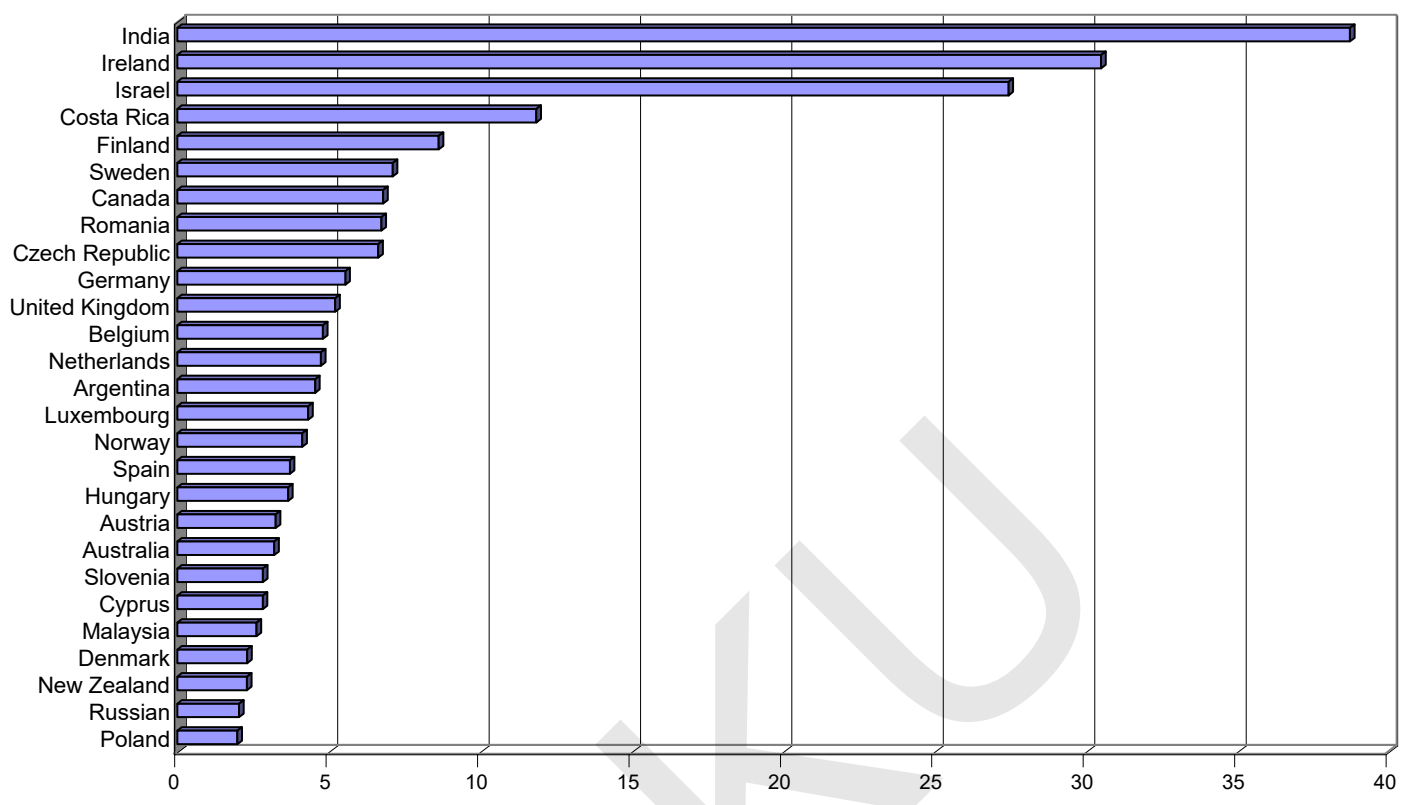

Source: Houghton, J.W. and Welsh, A. (2009) Australian ICT Trade Update 2009, Australian Computer Society, Sydney.

Assessing the possibility of alternative development pathways, Berkhout et al. (2009) argue that the convergence of economic structures and growth rates, which plays such a central role in growth theories, does not imply that the emergence of socio-technical systems underpinning growth must also be convergent in terms of their technological composition and environmental quality, and call for greater attention to the resource and environmental quality of development as the basis of more sustainable development pathways.

\section{ICT and the environment}

The relationship between ICTs and the environment is complex and multifaceted, as ICTs can play both positive and negative roles. Positive impacts can come from dematerialization and online delivery, transport and travel substitution, a host of monitoring and management applications, greater energy efficiency in production and use, and product stewardship and recycling. Negative impacts can come from energy consumption and the materials used in the production and distribution of ICT equipment, energy consumption in use directly and for cooling, short product life cycles and e-waste, and exploitative applications (e.g. remote sensing for unsustainable over-fishing (Daly 2003)).

The impacts of ICT on the environment can be direct (i.e. the impacts of ICTs themselves, such as energy consumption and e-waste), indirect (i.e. the impacts of ICT applications, such as 
intelligent transport systems, buildings and smart grids), or third-order and rebound (i.e. the impacts enabled by the direct or indirect use of ICTs, such as greater use of more energy efficient transport). Exactly what the impacts of ICT are, and to what extent there may be rebound effects (Box 1), are widely discussed topics. However, it is clear that attempts to measure the impacts of ICT on the environment should take account of the potential rebound effects and the entire life cycle, rather than simply the direct impacts of the product or application itself (Plepys 2002; Yi and Thomas 2007; Hilty 2008; etc.).

Estimates of the direct impacts of the ICT industries vary with the definition of the industry and coverage of ICT-related energy uses, but the production and use of ICT equipment is estimated to be equivalent to $1 \%$ to $3 \%$ of global $\mathrm{CO}_{2}$ emissions (including embedded energy) and a higher and growing share of electricity use. In 2006, it was estimated that ICT equipment (excluding broadcasting) contributed around $2 \%$ to $2.5 \%$ of worldwide Greenhouse Gas (GHG) emissions $-40 \%$ of this was reported to be due to the energy requirements of PCs and monitors, $23 \%$ to data centres, $24 \%$ to fixed and mobile telecommunications, and $6 \%$ to printers (Kumar and Mieritz 2007). More recent life cycle assessments produce broadly similar results (Malmodin 2009). Data centres are a particular focus, and Koomey (2007) estimated that worldwide electricity use for servers doubled between 2000 and 2005, and he suggested that consumption would increase by a further $40 \%$ by 2010 .

Nevertheless, the indirect enabling impacts of ICTs are greater, and a number of studies have identified potentially significant net positive impacts from ICTs. For example, The Climate Group (2008) identified key areas of enabling impacts potentially leading to global emissions reductions by 2020 that were five times the ICT sector's direct footprint (Figure 3).

Figure 3: $\quad$ ICT Impact: The global footprint and the enabling effect

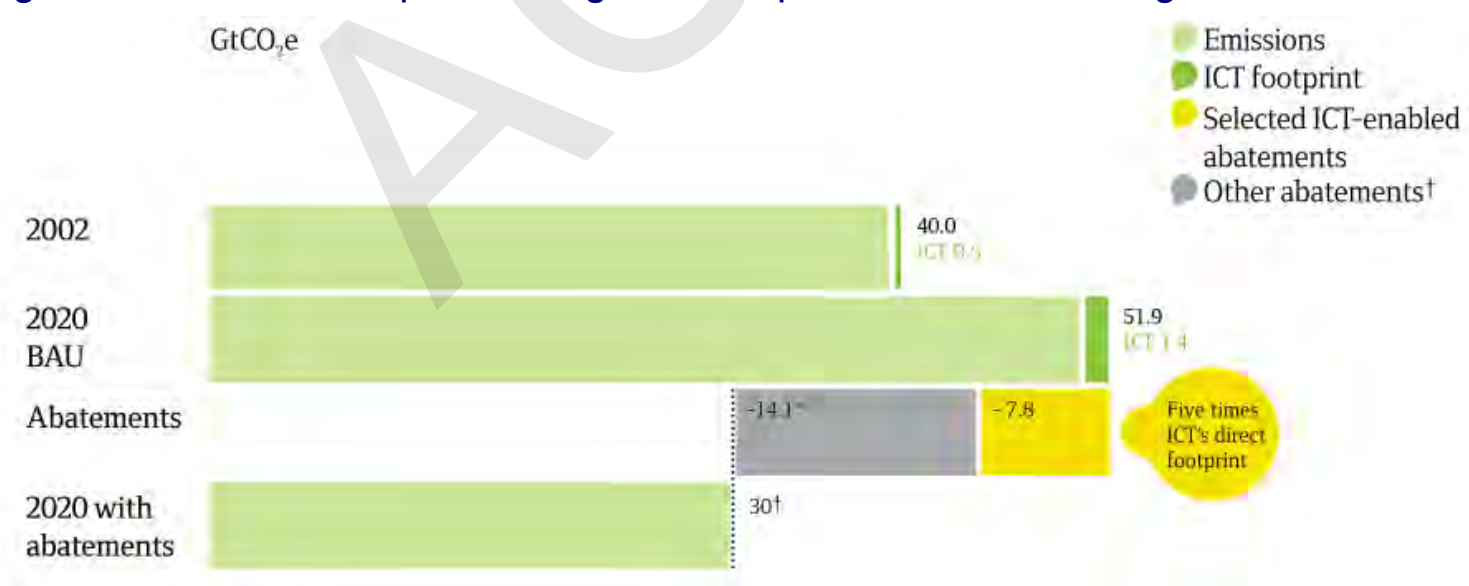

Source: The Climate Group (2008) SMART 2020: Enabling the low carbon economy in the information age, London, p15.

ICT and the Internet are enabling an increasing number of products and services to be delivered online (i.e. de-materialisation). This affects scientific journals, books, music CDs, film and videos, software, etc., with fewer taking a physical form and less energy and potentially fewer resources being used in their production, storage and delivery. E-commerce and online shopping 
can save time and travel in searching and pricing, and centralised fulfilment and delivery can replace many thousands of individual trips, not only saving energy directly but also through potential reductions in traffic congestion. E-mail has replaced many millions of letters, written on paper, collected, sorted and delivered worldwide, with almost instantaneous communication that has a very small environmental footprint (Schmidt and Kloverpris 2009).

ICTs offer the potential for transport and travel substitution. With tele-work or e-work the reduction of transport and commuting time can be substantial and considerable benefits can accrue for individuals, employers and the community. The reduction of long distance travel possible as a result of the use of data, voice and video applications over IP for webcasts, teleconferencing and video-conferencing can also be significant, and there are both direct impacts in terms of the environmental footprint and indirect impacts such as reduced demand on transport infrastructures and office facilities.

ICTs can also contribute to the resource and energy efficiency of many physical products embedded in either the products themselves or their production processes. For example, automotive electronics in the form of ignition chips have greatly improved the energy efficiency of motor vehicles, and industrial and household equipment and the design, construction and management of buildings increasingly includes ,smart technology to better control resource and energy use, emissions, serviceability and durability.

Nevertheless, there have been many studies pointing the difficulties in avoiding rebound effects and realising the potential benefits (see Box 1), and it has been noted that the ,paperless office ${ }^{e e}$ has not yet eventuated, e-commerce may not save energy if it encourages long distance delivery, tele-working can increase the home use of energy and demand for electronic equipment, such as routers and printers, and so on (Plepys 2002). As always, the key is not the technology, but how it is implemented and used.

Looking at ICTs as tools for dealing with environmental issues from a developing and emerging country perspective, ITU (2008) noted six application categories (Figure 4).

1) Environmental observation: terrestrial (earth, land, soil, water), ocean, climate and atmospheric monitoring and data recording technologies and systems (remote sensing, data collection and storage tools, telemetric systems, meteorological and climate related recording and monitoring system), as well as geographic information systems (GIS).

2) Environmental analysis: once environmental data have been collected and stored, various computational and processing tools are required to perform the analysis. This may include land, soil, water and atmospheric quality assessment tools, including technologies for analysis of atmospheric conditions including GHG emissions and pollutants, and the tracking of both water quality and availability. The analysis of data may also include correlating raw observational data with second order environmental measures, such as biodiversity.

3) Environmental planning: at the international, regional and national level, planning makes use of the information from environmental analysis as part of the decisionmaking process for the purpose of policy formulation and planning. Planning activities may include classification of various environmental conditions for use in agriculture 
and forestry and other applied environmental sectors, and is often focused on specific issues such as protected areas, biodiversity, industrial pollution or GHG emissions. Planning may also include the anticipation of environmental conditions and emergency scenarios, such as climate change, man-made and natural disasters.

4) Environmental management and protection: involves everything related to managing and mitigating impacts on the environment as well as helping adapt to given environmental conditions. This includes resource and energy conservation and management systems, GHG emission management and reduction systems and controls, pollution control and management systems and related methodologies, including mitigating the ill effects of pollutants and man-made environmental hazards.

Figure 4: $\quad$ ICT application categories

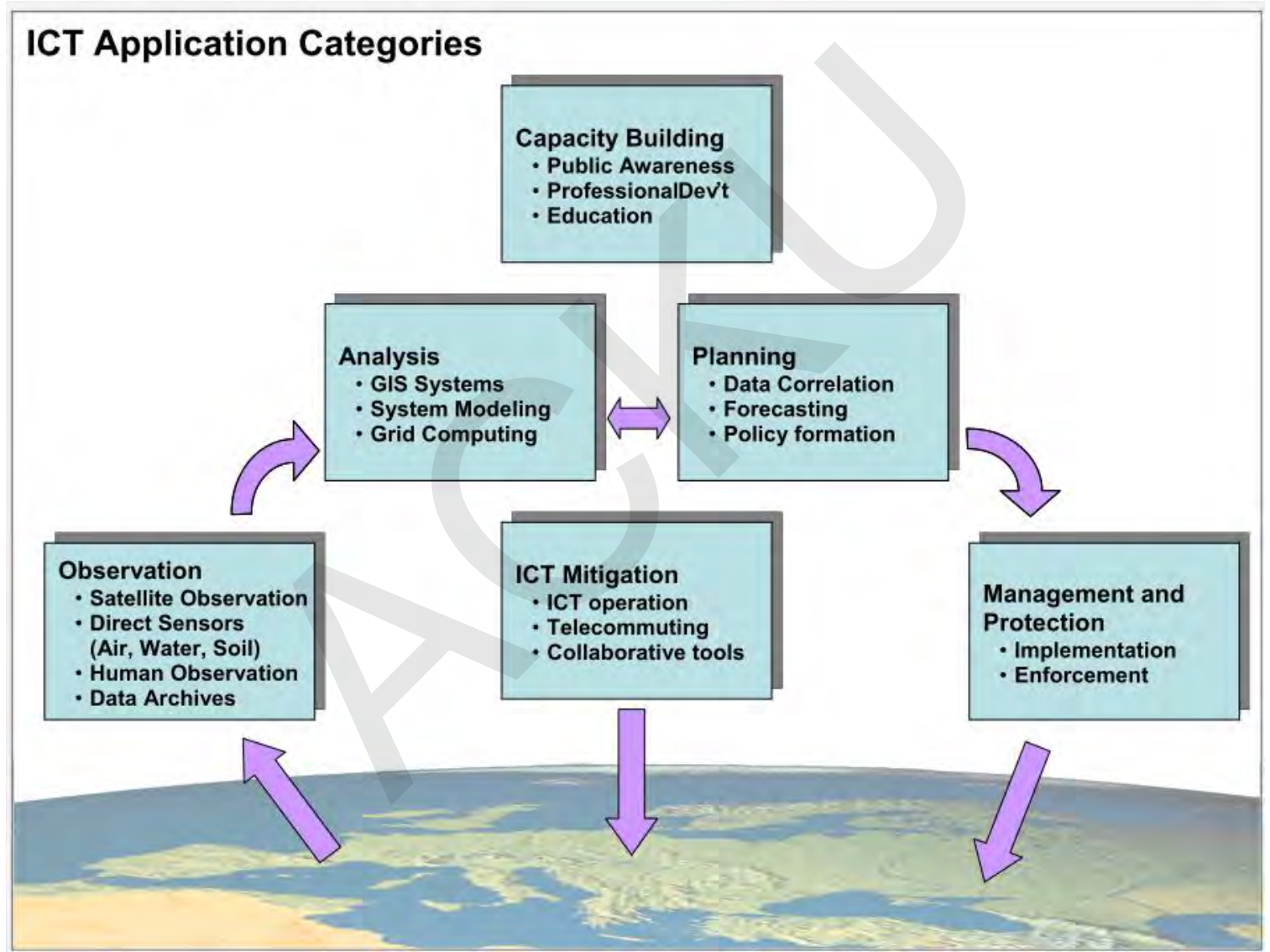

Source: ITU (2008) ICTs for e-Environment: Guidelines for developing countries, with a focus on climate change, ITU, Geneva, p25.

5) Impact and mitigating effects of ICT utilization: producing, using and disposing of ICTs require materials and energy and generate waste, including some toxic waste in the form of heavy metals. ICT use can mitigate the environmental impacts directly by increasing process efficiency and as a result of dematerialization, and indirectly by virtue of the secondary and tertiary effects resulting from ICT use on human activities, which in turn reduce the impact of humans on the environment. 
6) Environmental capacity building: efforts to improve environmental conditions rely on the actions of individuals and organizations. Capacity building includes efforts to increase public awareness of environmental issues and priorities, the development of professionals, and integrating environmental content into formal education.

This paper explores some examples of the role ICTs play in climate change mitigation, mitigating other environmental pressures, climate change adaptation and international cooperation.

\section{Mitigation: Avoiding the unmanageable}

Mitigation activities are directed at reducing the adverse impacts of climate change on the environment and are crucial to meeting emissions targets. Such activities can be focused on mitigating climate change directly or at a range of other environmental effects (e.g. water availability and salinity, desertification and deforestation).

\section{Climate change mitigation}

There are numerous ways in which ICTs can be used to mitigate environmental impacts, including through their contribution to measuring, monitoring and managing, and enabling more efficient use of resources and operation of infrastructures, through dematerialisation (e.g. online delivery of content, such as newspapers, books and music) and transport substitution (e.g. teleand video-conferencing), and intelligent transport systems, logistics and freight rationalisation, smart buildings and home automation. There are many studies and reports identifying areas in which ICTs can have a major impact on the environment, with a number identifying the energy efficiency in buildings and transport rationalization and substitution through dematerialisation, tele- and video-conferencing and tele-work as the major areas of impact based on sectoral energy use shares and trends, as well as application opportunities (e.g. Climate Risk 2008). 
Figure 5: Delivered energy consumption by sector in the US

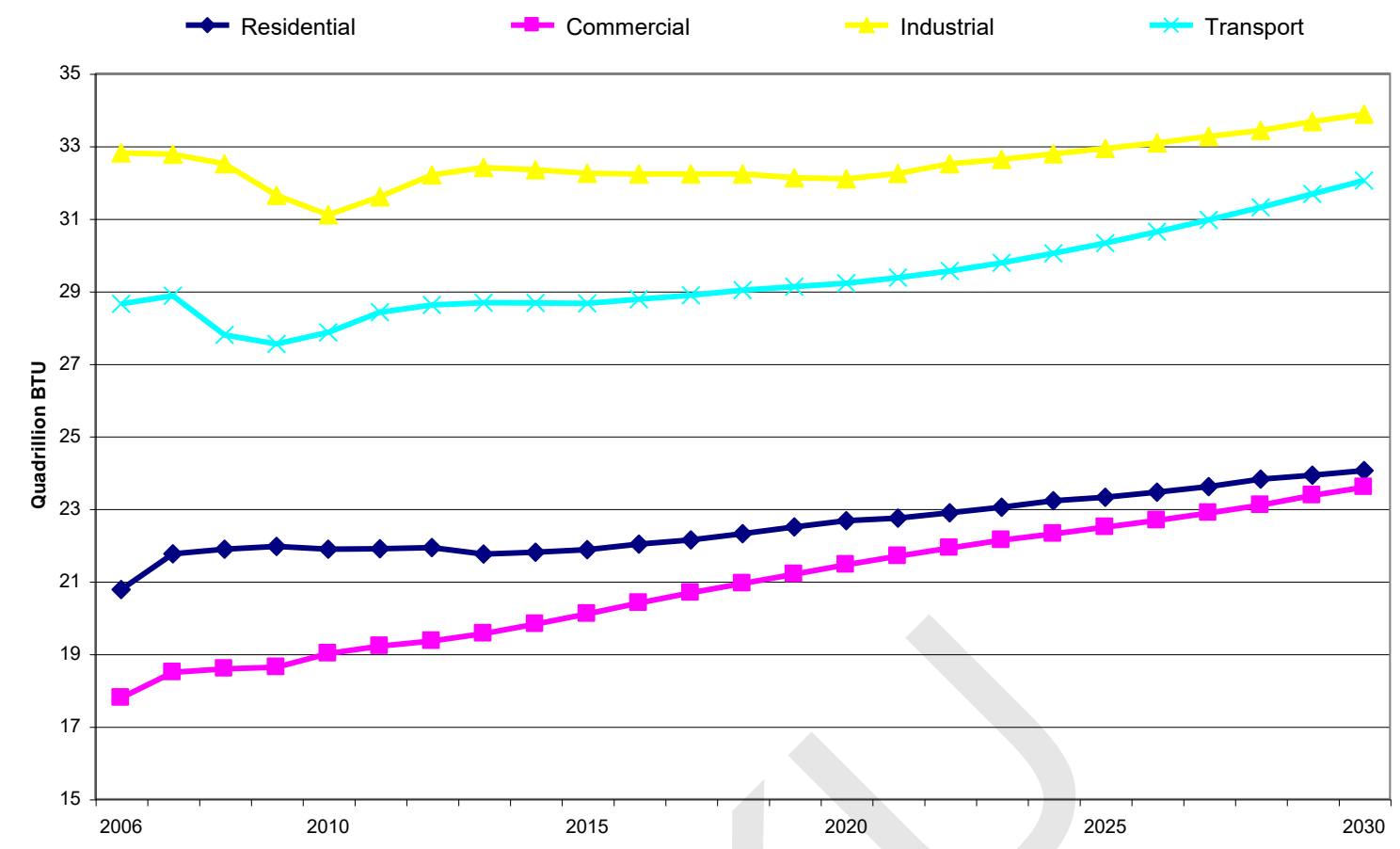

Source: EIA (2009) Annual Energy Outlook 2009, EIA, Washington DC. CSES Analysis.

Developing and emerging economies face many challenges in the provision of infrastructures as economic growth progresses, with rapidly increasing demand for reliable electricity supply, transport infrastructures and commercial buildings. The very difficulties faced in meeting rapidly growing demands can, and are, driving investments towards more energy efficient solutions. The Climate Group (2008) cited a number of examples.

Energy infrastructure: Smart Grids entail the modernisation of electricity distribution networks through the introduction of ICT and sensing network technologies. Smart grids enable improved monitoring and control of the energy network as a supply chain, which means reductions in energy losses, greater network operational efficiency, better quality and reliability of energy supply, greater customer control of their energy use, better management of highly distributed sources of energy generation (e.g. greater solar and wind generation), and reductions in greenhouse gas emissions. Smart meters add the possibility of two-way communication and supply between providers and users (Access Economics 2009), and play a vital role in making energy and environmental issues visible to the household consumer, thereby informing and empowering consumers and enabling behavioural change.

Electricity generation capacity limitations and grid transmission and distribution losses are driving ,smart gridee developments in India and China which are both improving energy use efficiency and reducing the rate of expansion of what are largely coal-fired electricity generation systems. Electricity generation accounts for $57 \%$ of Indiaes total emissions and with rapidly increasing demand those emissions are forecast to increase by $4 \%$ per annum, twice the global average. But, it is estimated that as much as $32 \%$ of generated power is lost along the grid (The Climate Group 2008). 
With infrastructure investments for the next 20-30 years now taking place, there is an opportunity to ,leapfrog "e to smart grid systems, to reduce power losses and outages and realise greater energy efficiency, and Indian distributors are looking to smart grid investments (e.g. North Delhi Power). In view of potential rebound effects (Box 1), market and price signals will be particularly important in emerging and developing economies.

\section{Box 1: $\quad$ Rebound effects?}

One major concern is that efficiency gains may result in lower energy costs and, thereby, increased use, such that the potential emissions reductions from energy efficiency gains are lost to ,rebound effects"e. These can be direct (e.g. where a fuel efficient vehicle enables someone to drive further at no additional costs), or indirect (e.g. where the fuel costs saved are spent on other energy intensive activities, such as a long distance flight).

In one of the most comprehensive reviews of the evidence on ,rebound effects ${ }^{\text {ee }}$, Sorrell (2007) noted, inter alia, that:

- Both direct and indirect effects appear to vary widely between different technologies, sectors and income groups and in most cases they cannot be quantified with much confidence. However the evidence does not suggest that improvements in energy efficiency routinely lead to economy-wide increases in energy consumption. At the same time the evidence suggests that economy-wide rebound effects will be at least $10 \%$ and often higher.

- There are very few studies of rebound effects from energy efficiency improvements in developing countries. Rebound effects may be expected to be larger in developing countries where demand for energy services is far from saturated.

- Energy efficiency may be encouraged through policies that raise energy prices, such as carbon taxes, or through non-price policies such as building regulations. Both should continue to play an important role in energy and climate policy. However, where rebound effects are expected to be large, there may be a greater need for policies that increase energy prices.

- Carbon/energy pricing can reduce direct and indirect rebound effects by ensuring that the cost of energy services remains relatively constant while energy efficiency improves.

Source: Sorrell, S. (2007) The Rebound Effect: An Assessment of the Evidence for Economy-wide Energy Savings from Improved Energy Efficiency, UKERC. Available http://www.ukerc.ac.uk/

Motor systems: Motor systems convert electricity into mechanical power, and while invisible to most of us they are crucial to the manufacturing sector"s energy use. Motors can be inefficient if they operate at full capacity, regardless of load. A motor is ,smart "e when it can be controlled to adjust its power usage to a required output through a variable speed drive and intelligent motor controller. It is estimated that the motor systems in operation in China use $70 \%$ of total industry electricity consumption and are 20\% less energy efficient than those in Western countries. By 2020, industrial motor systems in China will be responsible for an estimated 34\% of power consumption and $10 \%$ of carbon emissions, or $1-2 \%$ of global emissions. Industrial energy use in China could be reduced by $10 \%$ by improving the efficiency of motor systems, as motor system optimisation alone could reduce China's emissions by $200 \mathrm{MtCO}_{2} \mathrm{e}$ by $2020-$ comparable to total 2006 emissions from the Netherlands (The Climate Group 2008). 
Recognising the potential, China's government has implemented the China Motor Systems Energy Conservation Program to help reach its energy efficiency targets. It is unlikely that the necessary investments would be made without such initiatives.

Buildings: Energy consumption in buildings is driven by two factors - energy intensity and surface area. ICT-based monitoring, feedback and optimisation tools can be used to reduce both at every stage of a buildinges life cycle, from design and construction to use and demolition. Energy modelling software can help architects determine how design influences energy use. Builders can use software to compare energy models with actual construction. Once the building is complete, ICT can measure and benchmark its performance and compare actual to predicted energy efficiency. Occupants can install a building management system (BMS) to automate building functions such as lighting, heating and cooling and if a building undergoes a change of use, ICT can be used to redesign its energy model and measure the impacts of this change. It has been estimated that such tools could reduce the emissions from buildings by $15 \%$ by 2020 (The Climate Group 2008). Building standards and regulation are crucial elements in achieving such savings.

Transport: Globalisation has led to increasingly complex international supply chains and brings with it challenges for transport, storage and logistics operations. ICT can improve the efficiency of logistics operations in a number of ways. These include software to improve the design of transport networks, allow the running of centralised distribution networks and management systems that can facilitate flexible home delivery services. Specific levers include inter-modal shift, route optimisation and inventory reduction. The transport sector is a large and growing emitter of GHGs, responsible for $14 \%$ of global emissions, and it is estimated that optimising logistics using ICT could result in a $16 \%$ reduction in transport emissions and a $27 \%$ reduction in storage emissions globally (The Climate Group 2008). Many policy and regulatory issues influence transport and logistics, from airline route regulation, to building planning and regulation, and noise and pollution regulations relating to transport (Houghton 2005), presenting a major challenge for policy coherence.

\section{Mitigating other environmental pressures}

Developing economies are often dependent on agriculture and fishing for both cash crops and subsistence, and water can be a more pressing issue in emerging and developing economies than is energy use, and deforestation can also be a major concern in some regions. Hence, mapping, monitoring and managing lands, forests and waterways are crucial to the efficiency and sustainability of key sectors. Geographic Information Systems (GIS) provide major opportunities in land and waterway monitoring and management in Egypt (IISD 2005), Africa and across South East Asia and the Himalayan region (IISD 2009). As elsewhere, information is the key to enabling people to make more sustainable choices and realise benefits from their actions, as well as for education, awareness and support.

Observational data are increasingly available to users around the world through a range of portals and systems, allowing for environmental observation and prediction. Examples include the Earth Observation Portal ${ }^{1}$ and Climate Change Prediction Net, ${ }^{2}$ while conservation is the

1 http://www.eoportal.org/ 
focus of the Society for Conservation "s portal. ${ }^{3}$ There is an increasing tendency to make geospatial environmental information more readily available through the use of common interfaces, such as Google Earth and Microsoft's Virtual Earth. This enables information holders to make geo-specific information available to users through a standard web interface at very low cost. Examples include: The Tropical Ecology Assessment and Monitoring Network, ${ }^{4}$ Atlas of Our Changing Environment, ${ }^{5}$ Climate Change in Our World, ${ }^{6}$ and others. ${ }^{7}$

On the ground in developing countries there are a number of examples of how cellular mobile phones and wireless networks can provide a leapfrogging opportunity where fixed line networks are rudimentary or simply do not exist. Noting that agriculture is the mainstay of the Kenyan economy, Mungai (2005) provided a number of examples relating to mitigation, such as the SokoniSMS service, which enables farmers to receive market prices in various market centres through their mobile phones. ${ }^{8}$ Equipped with this information, the farmers are able to determine the most profitable market to transport products to, circumventing middlemen who usually offer to buy the products at much lower prices and reducing the tendency to transport goods from market to market in search of buyers. Other initiatives include the use of geographical information systems in the Lake Victoria basin (Mungai 2005) and along the Nile basin (Sobeih 2005) to support natural resource management and local development. These systems can be supplemented by location or eco-system specific information kits, such as The Mekong and Nile River Awareness Kits. ${ }^{9}$ Integrated eco-system monitoring, sensing and modelling is also increasingly common (e.g. The Pearl River Delta (Chan 2009)).

Noting the vulnerabilities of rural communities in South East Asia and the Himalayan regions, their dependence of eco-systems and pressures from unsustainable and over use, Tyler and Fajber (2009) noted the importance of access to information and a number of innovative projects. For example:

- In Indonesia, Bogor Agricultural University is working with farmers to use climate forecasts through climate field schools, and when seasonal forecasts suggested a drier than normal crop season in 2006-07, farmers stored a larger proportion of their first rice crop in anticipation of higher prices due to dry conditions for the second crop.

- In the Philippines, the Manila Observatory (MO) has partnered with SMART, one of the countryes mobile phone service providers, for a pilot project providing telemetric rain gauges and phones in disaster-prone areas. Local farmers read the rain gauges and phone the information to the Observatory, while the Observatory can also use the

2 http://www.climateprediction.net/

3 http://www.scgis.org/

4 http://www.teamnetwork.org

5 http://na.unep.net/digital_atlas $2 /$ google.php

6 http://earth.google.co.uk/outreach/kml_entry.html\#tClimate\%20Change\%20In\%200ur\%20World

7 http://earth.google.co.uk/outreach/kml listing.html\#cenvironment\%20science\#s1\#e20

8 http://www.gkpnet.org/projects/public/ict4dinitiatives/view.do?gkpprojectid=32600

9 http://www.mrcmekong.org/ and http://www.nileteap.org/nrak/ 
phones to issue early warning of storms to the farmers. In addition, the farmers can use the phones to access market information.

There are also many examples of supporting information networks (see below).

\section{Adaptation: Managing the unavoidable}

Adaptation refers to actions designed to reduce the negative impacts of climate change that are already occurring. Unfortunately, the most vulnerable are at most risk, and for the developing world it is the role that ICTs can play in climate change monitoring and adaptation that is likely to be most important (infoDev 2009). Examples of adaptation include preparing risk assessments, protecting ecosystems, improving agricultural methods, managing water resources, instituting better building designs and building settlements in safe zones, developing early warning systems, improving insurance coverage and developing social safety nets (ISDR 2008; ITU 2008).

\section{Climate change adaptation}

Monitoring and providing early warning of climate change induced events, such as storm and tsunami, drought and flood, famine and disease, play a vital role. Examples at the international level include:

- $\quad$ The Famine Early Warning Systems Network (FEWS NET), a USAID-funded network that brings together international, regional and national partners to provide early warning and vulnerability information on emerging and evolving food security issues. FEWS NET professionals in Africa, Central America, Haiti, Afghanistan and the United States monitor and analyse climate information for potential impacts on livelihoods and markets to identify potential threats to food security. Once identified, FEWS NET uses a suite of communications and decision support technologies to help decision makers act to mitigate food insecurity. These include monthly food security updates for 25 countries, regular food security outlooks and alerts, as well as briefings and support to contingency and response planning efforts. ${ }^{10}$

- Distant Early Warning System for Tsunami (DEWS) is a tsunami warning system for the Indian Ocean, which aims to create a new generation of interoperable tsunami early warning systems based on an open sensor platform, which integrates sensor systems for the rapid detection of earthquakes, for the monitoring of sea level, ocean floor events, and ground displacements. Tsunami warnings can be sent via SMS to mobile cellular phones, by facsimile or as a television overlay. ${ }^{11}$

- PreventionWeb serves the information needs of the disaster risk reduction (DRR) community, including the development of information exchange tools to facilitate collaboration, providing a common platform for the disaster risk reduction community to find and share DRR information, exchange experience, connect and collaborate. ${ }^{12}$

\footnotetext{
10 http://www.fews.net

11 http://www.dews-online.org

12 http://www.preventionweb.net/
} 
Another area in which the use of ICTs supports adaptation is that of climate and impact models, which can be used to inform practitioners and decision makers in planning as well as predicting the impacts of climate change on agriculture (e.g. combined with crop models). SEI (2008) cite a number of examples, including:

- A South African study undertaken by the University of Pretoria that focused at the provincial level and found a significant correlation between higher historical temperatures and reduced dryland staple production, and forecast a fall in net crop revenues by as much as $90 \%$ by 2100 .

- A Nigerian study that applied the EPIC crop model to give projections of crop yield during the 21 st century. The study modelled worst case climate change scenarios for maize, sorghum, rice, millet and cassava, and found that there will be increases in crop yield across all low land ecological zones as the climate changes during the early parts of the 21 st century, but towards the end of the century the rate of increase will tend to slow down.

- An Egyptian study that compared crop production under current climate conditions with those projected for 2050, and forecast a decrease in national production of many crops, ranging from $-11 \%$ for rice to $-28 \%$ for soybeans.

- A study that mapped climate vulnerability with a focus on the livestock sector and identified arid and semi-arid rangeland and the drier mixed agro-ecological zones across the African continent, particularly in Southern Africa and the Sahel, and coastal systems in East Africa as being particularly prone to climate change (Thornton et al. 2006).

Similarly, ICRISAT's integrated climate risk assessment and management system uses remote sensing and GIS techniques to study rainfall patterns and prepare advisories for farmers in drylands of Asia and sub-Saharan Africa. ${ }^{13}$

Having identified areas of vulnerability, ICTs enable a range of responses, with information networks playing a crucial role. There are many examples:

- $\quad$ The Arid Lands Information Network (ALIN) states that its strategy is informed by the belief that knowledge is a source of competitiveness, where value lies in new ideas, practices, information on opportunities and new technologies as drivers of this process; that knowledge improves lives, reduces poverty and empowers people; that access to knowledge is fundamental to development and progress; and that ICTs are key for enabling access to knowledge. ALIN provides an information sharing forum that helps people to adjust to climate change. ${ }^{14}$

- $\quad$ RANET uses radio and the Internet for the communication of hydro-meteorological information for rural development, and includes the use of SMS emergency altering systems and community-based weather observation. ${ }^{15}$

\footnotetext{
13 http://www.icrisat.org/

14 http://www.alin.or.ke/

$15 \mathrm{http} / / / \mathrm{www}$. ranetproject.net/
} 
- The Open Knowledge Network (OKN) and openeNRICH also provide regular information relating to climate change adaptations, such as the recent exchange "Climate change increases food insecurity in Kyuso, Kenya" (09-07-2009). ${ }^{16}$

- Focusing on mountain regions the Mountain Forum and its regional partners provide information to enable residents of mountain regions to adapt to climate change (e.g. Climate Change and the Himalayas $\left.{ }^{17}\right) .18$

Periodicals, such as I4D, ${ }^{19}$ telecentre magazine, ${ }^{20}$ newsfordev, ${ }^{21}$ Worldchanging, ${ }^{22}$ etc. provide many examples, and a number of international ICT4D agencies operate environment related programs $\left(\right.$ e.g. $\left.\mathrm{IICD}^{23}\right)$. Links and overviews can be seen through such sites as scidevnet, ${ }^{24}$ $\mathrm{km} 4 \mathrm{dev},{ }^{25} \mathrm{t} 4 \mathrm{~cd},{ }^{26} \mathrm{etc}$.

\section{International co-operation}

Environmental issues are by their nature global and, while local action is required, international cooperation is essential. Key areas include: providing and operating the infrastructures for monitoring and early warning; collecting, analysing and disseminating the information necessary to enable governments and other agencies to manage, mitigate and adapt to climate change; building capabilities, transferring technology and the funding necessary to enable its use.

\section{Technology transfer}

The Bali Action Plan included the commitment to help developing countries undertake nationally appropriate mitigation actions in the context of sustainable development without compromising growth, by transferring finance and technology from developed countries in a measurable, reportable and verifiable manner (World Bank 2008). While there are many examples of technology awareness and transfer activities, it is probably the transfer of technology and funding that are the most challenging and among the most pressing issues.

TT:clear: The UNFCCC expert group on technology transfer operates a technology information clearinghouse (TT:clear), which offers a web-based information sharing platform for access to a variety of sources of information including case studies. ${ }^{27}$ The objective is to provide useful

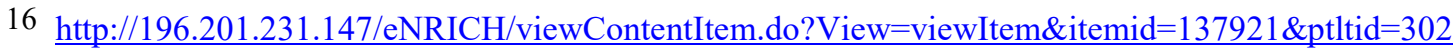

17 http://www.icimod.org/home//pub/publications.content.php?puid=126

$18 \mathrm{http}: / /$ www.mtnforum.org/index.cfm and http://www.mtnforum.org/rn/index.cfm

$19 \mathrm{http}: / / \mathrm{www}$. i4donline.net/articles/current-article.asp?articleid=1910\&typ=Features

$20 \mathrm{http}: / / \mathrm{www} \cdot$ telecentremagazine.net/

21 http://www.newsfordev.org/index.html

22 http://www.worldchanging.com/

$23 \mathrm{http}: / / \mathrm{www}$.iicd.org/sectors/environment

24 http://www.scidev.net/en/climate-change-and-energy/

25 http://www.km4dev.org/

26 http://www.t4cd.org/

27 http://unfccc.int/ttclear/jsp/index.jsp
} 
information to stakeholders on all aspects of technology transfer for climate change mitigation and adaptation. TT:clear aims to help countries take advantage of opportunities for technology transfer by helping them become more aware of the technologies available, of the funding and other forms of assistance that exists for them, and to show them case studies that they can use when developing proposals or undertaking projects. It also provides for the exchange of views and experiences on the development and transfer of technologies (ITU 2008).

The Climate Change Information Network: CC:iNet is a web portal that serves as a clearinghouse for information sources on public information, education and training in the field of climate change. It is designed to help governments, organizations and individuals gain rapid and easy access to ideas, strategies, contacts, experts and materials that can be used to motivate and empower people to take effective action on climate change. ${ }^{28}$

GIS Development: is a Geospatial Communication Network that promotes the use of GIS technology and applications in various areas of development. It assists communities and governments in developing their productivity, policies and management capabilities by facilitating knowledge transfer, and it fosters the growing network of those interested in geoinformatics and encourages the exchange of scientific know-how through magazines, a portal, conferences and training. GIS development claims to be the world's largest geospatial technical resource portal, with over 20,000 pages on various aspects of geospatial sciences. It is ranked among the top 100,000 websites and draws 140,000 unique visitors every month making it one of the most popular destinations in the field. ${ }^{29}$

Energy Sector Management Assistance Program (ESMAP): is a global technical assistance program which helps build consensus and provides policy advice on sustainable energy development to governments of developing countries and economies in transition. ESMAP also contributes to the transfer of technology and knowledge in energy sector management and the delivery of modern energy services to the poor. ${ }^{30}$

Combining information with research and education Australiaes Desert Knowledge provides information, expertise and experience relating to adapting to desertification, while sites such as $\mathrm{km} 4 \mathrm{dev}$, scidevnet and $\mathrm{t} 4 \mathrm{~cd}$ provide a wealth of information relating to climate change mitigation and adaptation and development. ${ }^{31}$ This international flow of information, demonstration projects and on-the-ground experiences and learning plays a vital role in technology transfer.

\section{Sustainable ICT value and supply chains}

The very processes of development and globalisation have draw far-flung regions into global distribution and logistics networks, making international co-operation essential in such areas as

\footnotetext{
28 http://unfecc.int/cc_inet/items/3514.php

29 http://www.gisdevelopment.net/aboutus/portal.htm

$30 \mathrm{http}: / / \mathrm{www}$. esmap.org/

31 http://www.desertknowledge.com.au/ $\quad$ http://www.km4dev.org/ $\quad$ http://www.scidev.net/ http://www.t4cd.org
} 
standardisation of energy efficiency monitoring and labelling, and international trade in electronic waste (e-waste).

\section{Cross-border trade in e-waste}

Electronic waste or e-waste is a growing problem, and is one of the fastest growing sources of waste. The United Nations has estimated that some 20 to 50 million tonnes of e-waste are generated each year, and recent European studies suggest that e-waste is increasing around three times faster than the total waste stream, accounting for around $8 \%$ of all municipal waste (Vetter and Creech 2008).

While miniaturisation and the trend towards the use of mobile devices and LCD screens reduces the energy consumption impacts of ICT equipment, its rapid adoption in households and developing and emerging economies, together with short product life cycles, is contributing to continuing increases in energy use and in the production of e-waste. This is exacerbated by the increasing use of electronics in motor vehicles, home appliances and almost all forms of industrial and consumer equipment (Bio Intelligence 2008).

There have been major gains in reducing the use of materials of concern in electronic equipment and in legitimate recycling initiatives, but much that is collected is still being leaked to substandard treatment plants or illegally exported. ${ }^{32}$ Greenpeace reported that inspections of 18 European seaports in 2005 found that as much as $47 \%$ of waste destined for export, including ewaste, was illegal. Despite attempts by governments to ban the illegal export and import of ewaste, India, China and Africa (e.g. Ghana and Nigeria) remain major destinations. ${ }^{33}$

Many of the major ICT and electronics firms are trying to clean up the e-waste problem with pro-active return and re-cycling initiatives, but these tend to affect local recycling more than the international trade in e-waste. International cooperation can help to stop the illegal trade and to ensure that recycling operations meet appropriate standards. This may be through updating the Basel Convention, regional or bi-lateral agreements, tracing and monitoring or other regulatory mechanisms, but the problem is not easy to solve as banning trade and forcing local recycling would be likely to raise the cost of and thereby discourage recycling. It may be that local implementation and monitoring of internationally agreed standards for recycling is the only effective course of action (Shinkuma and Huong 2009).

\section{Summary and conclusions}

ICTs are all but ubiquitous and the potential uses and impacts of ICTs on the environment are many and varied. No short paper can cover all aspects, and this paper does no more than provide a few examples. However, it is possible to note some of the key areas of impact and potential in more general terms, highlighting some of the major issues arising for policy coherence.

32 http://europa.eu/rapid/pressReleasesAction.do?reference=MEMO/08/764

$33 \mathrm{http} / / / \mathrm{www} . g r e e n p e a c e . o r g /$ international/campaigns/toxics/electronics/where-does-e-waste-end-up\# 
There are a number of crucial tasks and tools, including:

- Earth observation, remote sensing and monitoring, communications networks, grid and cloud computing, data collection, analysis and modelling, database management and decision support systems;

- Geographic information systems (GIS) and earth browsers (e.g. Google Earth and Visual Earth);

- Web-based clearing house sites for communicating technology and learning, education and capability building; and

- Monitoring and reporting on, and operation of, transaction systems and trading.

Specific applications include:

- Detection and early warning (e.g. storm, flood, earthquake and tsunami warning);

- $\quad$ Energy efficiency applications (e.g. intelligent building systems, intelligent transport systems, smart grids and home automation); and

- Information, education and capability building (e.g. technology awareness and transfer, public education and support), with the key to realising potential benefits being behavioural change at the household and individual level.

Key issues for emerging and developing countries include:

- Access to infrastructure and ways to enable investments in smarter greener energy, transport and building infrastructures, as well as access to the broadband networks and ICT equipment and services necessary to enable their operation;

- Access to data and how the masses of data collected can be brought together to provide a holistic picture of an eco-system or environment (i.e. who owns the data, who can use it and what can it be used for?);

- Affordability and how emerging and new technologies can be implemented in contexts of severe budgetary constraint; and

- Capability and how the necessary skills can be brought to bear on environmental issues in developing and emerging economies.

Areas for concern for developing and emerging economies include:

- Understanding life cycle impacts in the many different contexts and circumstances that exist in developing and emerging economies, and not assuming that developed country life cycle assessments will apply, while operating within the constraints of available data (e.g. insufficient national statistical collections to support input-output analysis and life cycle assessments);

- Managing possible rebound effects, which are likely to be greater in rapidly growing markets where there is unmet demand for energy and resources, and the related difficulties of establishing an equitable international price for carbon and regulating for appropriate price signals; and 
- Ensuring that there is sufficient technology transfer and enabling funding flows to developing countries.

Fundamentally, ICTs are about information and communication, and it is these roles that are vital. Data must be collected, analysed and interpreted, transformed into information that enables individuals to make smarter greener choices, and communicated to individuals in such a way as to inform and educate, influence and change behaviours. It is not simply a matter of price signals shaping behaviour, even if it were possible to get those signals right, but also about informing, monitoring performance and providing non-price feedback in such a way as to motivate and reward individuals and communities for creating sustainable livelihoods.

As Plepys (2002) noted: “...it is necessary to look at both ecological and social dimensions. The positive ecological dimension rests on ICT's potential to deliver greener products, optimise the ways of their delivery, and increase consumption efficiency through dematerialisation, esubstitution, green marketing, ecological product life optimisation, etc. The environmental potential offered by the ecological dimension will be fully utilised only under an optimised social dimension, which deals with the behavioural issues of consumption." 


\section{References}

Access Economics (2009) The economic benefits of intelligent technologies, Access Economics, Canberra. Available http://www.accesseconomics.com.au/

Barton, J.H. (2008) Mitigating Climate Change Through Technology Transfer: Addressing the needs of developing countries, EEDP Pare 08/02, Chatham House, London. Available http://www.chathamhouse.org.uk/files/12357 1008barton.pdf

Basel Convention (2003) Report of the Conference of the Parties to the Basel Convention on the Control of Transboundary Movements of Hazardous Wastes and their Disposal, UNEP. Available www.basel.int/meetings/cop/cop6/english/Report40e.pdf

Berkhout, F., Angel, D. and Wieczorek, A.J. (2009) „Asian development pathways and sustainable socio-technical regimes, " Technological Forecasting \& Social Change 76 (2009) pp.218-228.

Berkhout, F., Angel, D. and Wieczorek, A.J. (2009) ,Sustainability transitions in developing Asia: Are alternative development pathways likely?ee Technological Forecasting and Social Change 76 (2009), pp.215-217.

Bio Intelligence (2008) Impacts of Information and Communication Technologies on Energy Efficiency, European Commission DG INFSO. Available http://cordis.europa.eu/fp7/ict/sustainable-growth/studies_en.html

Chan, E. (2009) „Dealing with the environmental problems of The Pearl River Delta Region

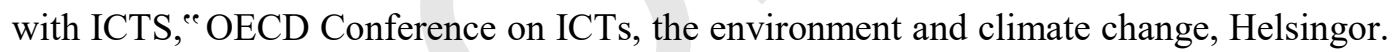
Available http://itst.media.netamia.net/ict2009/video.php?tab=demand

Climate Risk (2008) Towards a High-Bandwidth, Low-Carbon Future: Telecommunicationsbased opportunities to reduce greenhouse gas emissions, Climate Risk, Sydney. Available www.climaterisk.com.au

Daly, J. (2003) ICT and Ensuring Environmental Sustainability, Development Gateway (dgCommunities). Available http://topics.developmentgateway.org

EIA (2009) Annual Energy Outlook 2009, EIA, Washington DC. Available http://www.eia.doe.gov/oiaf/forecasting.html

EU/IST (2000) The Knowledge Economy and Climate Change: An Overview of New Opportunities, European Commission/IST. Available http://www.forseback.se/pdf/case climate.pdf

Ghosh, P. (2009) „The climate change debate: The story from India, $A$ Taxing Debate: Climate policy beyond Copenhagen, CEDA, Melbourne. Available http://www.ceda.com.au/public/publications/growth/growth 61.html

Global Action Plan (2007) An Inefficient Truth, Global Action Plan, London. Available http://www.globalactionplan.org.uk 
Herring, H. and Roy, R. (2002) ,Sustainable services, electronic education and the rebound effect, "Environmental Impact Assessment Review 22(2002), pp524-542.

Hilty, L.M. (2008) Information Technology and Sustainability: Essays on the relationship between information technology and sustainable development, Books on Demand, Norderstedt.

Houghton, J.W. (2005) Digital Delivery in Distribution and Logistics, OECD, Paris.

Houghton, J.W. and Welsh, A. (2009) Australian ICT Trade Update 2009, Australian Computer Society, Sydney. Available http://www.cfses.com

IISD (2005) A Developing Connection: Bridging the Policy Gap Between the Information Society and Sustainable Development, IISD, Winnipeg. http://www.iisd.org/publications/pub.aspx?pno $=740$

IISD (2009) Land and Water Resource Management in Asia: Challenges for climate adaptation, IISD, Winnipeg. http://www.iisd.org/climate/

InfoDev (2009) ICTs and Climate Change, infoDev. Available http://www.infodev.org/

ISDR (2008) Climate Change and Disaster Risk Reduction, UN/ISDR, Geneva. Available http://www.unisdr.org/

ITU (2008) ICTs for e-Environment: Guidelines for developing countries, with a focus on climate change, ITU, Geneva. Available http://www.itu.int/themes/climate/

Koomey, J. (2007) Estimating total power consumption by servers in the U.S. and the world, Analytics Press, Oakland. Available http://enterprise.amd.com/Downloads/svrpwrusecompletefinal.pdf

Kumar, R. and Mieritz, L. (2007) Conceptualizing Green IT and data center power and cooling issues, Gartner Research Paper. Available http://www.gartner.com/DisplayDocument?id=519717

Laitner, J.A. and Ehrhardt-Martinez, K. (2008) Information Technologies: the Power of Productivity, American Council for an Energy-Efficient Economy. Available http://www.aceee.org/pubs/e081.htm

Malmodin, J. (2009) „Life cycle assessments of ICT, environment and climate change, Helsingor. Available http://itst.media.netamia.net/ict2009/video.php?tab=demand

Mungai, W. (2005) „Using ICTs for Poverty Reduction and Environmental Protection in Kenya," in IISD A Developing Connection: Bridging the Policy Gap Between the Information Society and Sustainable Development, IISD, Winnipeg. Available http://www.iisd.org/publications/pub.aspx?pno $=740$

Murphy, D., Tirpak, D., Drexhage, J. and Gagnon-Lebrun, F. (2009) Encouraging Developing Country Participation in a Future Climate Change Regime, IISD, Winnipeg. Available www.iisd.org 
Plepys, A. (2002) „The grey side of ICT, Environmental Impact Assessment Review 22(2002), pp509-523.

Rock, M., Murphy, J.T., Rasiah, R., van Seters, P. and Managi, S. (2009) „A hard slog, not a leap frog: Globalization and sustainability transitions in developing Asia, ${ }^{\text {ee Technological }}$ Forecasting \& Social Change 76 (2009) pp.241-254.

Romm, J., Rosenfeld, A. and Herrmann, S. (1999) The Internet Economy and Global Warming: A Scenario of the Impact of Ecommerce on Energy and the Environment, The Centre for Energy and Climate Solutions, The Global Environment and Technology Foundation. Available www.p2pays.org/ref/04/03784/0378401.pdf

Schmidt, A. and Kloverpris, N.H. (2009) Environmental impacts from digital solutions as an alternative to conventional paper-based solutions, Assessment of e-Boks, Lyngby. Available http://ekstranet.e-boks.dk/

SEI (2008) Climate Change and Adaptation in African Agriculture, SEI, Stockholm. Available http://www.sei.se

Sheehan, P.J. (2008) „Beyond Industrialization: New Approaches to Development Strategy Based on the Services Sector," UNU-WIDER Research Paper 2008/60: Helsinki. Available $\quad$ http://www.wider.unu.edu/publications/working-papers/researchpapers/2008/en_GB/rp2008-60/

Shinkuma, T. and Huong, N.T.M. (2009), ,The flow of E-waste material in the Asian region and a reconsideration of international trade policies on E-waste, "Environmental Impact Assessment Review 29(1), pp25-31.

Sobeih, M. (2005) „Geographic Information Systems (GIS) in Egypt, " in IISD A Developing Connection: Bridging the Policy Gap Between the Information Society and Sustainable Development, IISD, Winnipeg. Available http://www.iisd.org/publications/pub.aspx?pno $=740$

Sorrell, S. (2007) The Rebound Effect: an Assessment of the Evidence for Economy-wide Energy Savings from Improved Energy Efficiency, UKERC. Available http://www.ukerc.ac.uk/

The Climate Group (2008) SMART 2020: Enabling the low carbon economy in the information age, London. Available http://www.smart2020.org/

Thornton P.K., Jones P.G., Owiyo T., Kruska R.L., Herrero M., Kristjanson P., Notenbaert A., Bekele N. and Omolo A., with contributions from Orindi V., Otiende B., Ochieng A., Bhadwal S., Anantram K., Nair S., Kumar V. and Kulkar U. (2006) Mapping climate vulnerability and poverty in Africa, Report to the Department for International Development, ILRI, Nairobi, Kenya.

Tyler, S. and Fajber, L. (2009) Land and Water Resource Management in Asia: Challenges for climate adaptation, IISD, Winnipeg. Available http://www.iisd.org/climate/

Vetter, T. and Creech, H. (2008) The ICT Sector and the Global Connectivity System: A sustainable development overview, The International Institute for Sustainable Development, IISD, Winnipeg. Available www.iisd.org 
Vetter, T. and Creech, H. (2008) The ICT Sector and the Global Connectivity System: A sustainable development overview, The International Institute for Sustainable Development, IISD, Winnipeg. Available www.iisd.org

World Bank (1993) The East Asian Miracle: Economic growth and public policy, The World Bank, Washington DC. Available http://www.worldbank.org/

World Bank (2008) Development and Climate Change, The World Bank, Washington DC. Available http://www.worldbank.org/

Yi, L. and Thomas, H.R. (2007) „A review of research on the environmental impact of ebusiness and ICT, Environment International 33, pp841-849. 